\title{
Optimization of Extraction Parameters by Using Response Surface Methodology, Purification, and Identification of Anthocyanin Pigments in Melastoma malabathricum Fruit
}

\author{
Nordiyanah Anuar, ${ }^{1}$ Ahmad Faris Mohd Adnan,, ${ }^{1,2}$ Naziz Saat, ${ }^{1}$ \\ Norkasmani Aziz, ${ }^{1,2}$ and Rosna Mat Taha ${ }^{1,2}$ \\ ${ }^{1}$ Institute of Biological Sciences, Faculty of Science, University of Malaya, 50603 Kuala Lumpur, Malaysia \\ ${ }^{2}$ Centre for Ionics, Department of Physics, University of Malaya, 50603 Kuala Lumpur, Malaysia \\ Correspondence should be addressed to Ahmad Faris Mohd Adnan; ahmad_farisz@um.edu.my
}

Received 29 July 2013; Accepted 21 August 2013

Academic Editors: R.-C. Sun and M. Talat

Copyright (C) 2013 Nordiyanah Anuar et al. This is an open access article distributed under the Creative Commons Attribution License, which permits unrestricted use, distribution, and reproduction in any medium, provided the original work is properly cited.

\begin{abstract}
Anthocyanins not just have various benefits in food industry but also have been used as natural colourants in cosmetic, coating products and as potential natural photosensitizers in solar cell. Thus, the main purpose of this study was to obtain information on the maximum yield of anthocyanin that can be recovered from Melastoma malabathricum fruit. Factors such as extraction temperature, extraction time, and solid to liquid ratio were identified to be significantly affecting anthocyanin extraction efficiency. By using three-level three-factor Box-Behnken design, the optimized conditions for anthocyanin extraction by acidified methanol $\left(R^{2}=0.972\right)$ were temperature of $60^{\circ} \mathrm{C}$, time of $86.82 \mathrm{~min}$, and $0.5: 35(\mathrm{~g} / \mathrm{mL})$ solid to liquid ratio while the optimum extraction conditions by acidified ethanol $\left(R^{2}=0.954\right)$ were temperature of $60^{\circ} \mathrm{C}$, time of $120 \mathrm{~min}$, and $0.5: 23.06(\mathrm{~g} / \mathrm{mL})$ solid to liquid ratio. The crude anthocyanin extract was further purified by using Amberlite XAD-7 and Sephadex LH-20 column chromatography. Identification of anthocyanins revealed the presence of cyanidin dihexoside, cyanidin hexoside, and delphinidin hexoside as the main anthocyanins in M. malabathricum fruit.
\end{abstract}

\section{Introduction}

Anthocyanins are identified as water soluble compounds having molecular structure based on a $\mathrm{C}_{6}-\mathrm{C}_{3}-\mathrm{C}_{6}$ skeleton. Anthocyanins are the most conspicuous subset under flavonoid group, due to the wide range of colours resulting from their synthesis [1]. They are responsible for the red, purple, and blue colours in many parts of the plants. Today, the interest in anthocyanins has arised due to their unique structure and beneficial health claims food and pharmaceutical industry have greatly benefited from. They have been used for various food preparations such as jelly dessert, milk dessert, soft ice-cream, hard ice-cream, and yogurt [2]. Besides being important in food and pharmaceutical industry, various natural dye extracts which include anthocyanins have also been actively explored by researchers to be used as sensitizer in dye-sensitized solar cells $[3,4]$ and coating [5].
These valuable bioactive compounds also have been reported to have biological effects on the physiological functions of cells such as reducing oxidative cell damage and increasing high density lipoprotein (HDL) cholesterol level $[6,7]$. Anthocyanins with an ortho-dihydroxyphenyl structure on the B-ring (e.g., delphinidin) may contribute to the induction of apoptosis on which its chemo preventive action against cancer is based [8]. Recently, researchers have found that cyanidin-3-glucoside could improve functional recovery of neurological dysfunction in a rat model having traumatic spinal cord injury while delphinidin-3-glucoside was found to have significant roles against thrombosis and cardiovascular diseases $[9,10]$.

Melastoma malabathricum, which belongs to the family Melastomataceae, is described as a flowering shrub that is distributed widely in South and Southeast Asia [11]. The fruits are considered as a rich source of anthocyanins as the fruits 
turned to dark purple when ripe. Previous works done on $M$. malabathricum were primarily on thephytochemical contents and medicinal properties obtained from the leaves, stems, and roots [12-14]. This shrub has the potential as a steady supply of feedstock for pigment production.

Extraction of the bioactive compound is influenced by various process parameters such as solvent composition, $\mathrm{pH}$, temperature, extraction time, and solid to liquid ratio $[15,16]$. Extracts rich in anthocyanins were usually extracted using methanol, ethanol, acetone, water, or mixtures and with the addition of small amount of acid which is recommended to prevent the degradation of the nonacylated compounds. Response surface methodology (RSM) is an economically efficient experimental procedure for optimizing this complex process. Compared to using "one to one factor" method, RSM is far better since in RSM the several process variables simultaneously interact with each other. This method is based on multivariate nonlinear model that has been widely used in chemical, biological, and agricultural applications to predict the optimal conditions of the systems.

To the best of our knowledge, there were no studies focusing on optimizing the parameters for anthocyanin extraction from M. malabathricum fruit. Thus, the objectives of this study were to obtain maximum yield of anthocyanin recovery from $M$. malabathricum fruit and also to identify the major anthocyanin components in M. malabathricum fruit using UPLC-ESI-MS/MS.

\section{Materials and Methods}

2.1. Materials. The chemical reagents (potassium chloride, sodium acetate) used in this study were of analytical grade and obtained from Sigma Aldrich. Methanol (99.8\%) and undenatured ethanol (99.8\%) from Systerm were used as extraction solvents. Ethyl acetate (Systerm) was used in the separation process. Formic acid, ammonium formate, and acetonitrile were of HPLC grade obtained from Merck. Sephadex LH-20 and Amberlite XAD-7 from GE Healthcare were used as chromatography resin. Deionized water used in this study was purified at $18.2 \mathrm{M} \Omega . \mathrm{cm}^{-1}$ (Barnstead RO \& Deionized Systems).

\subsection{Methods}

2.2.1. Sample Preparation. Fresh mature fruits of $M$. malabathricum were used as raw material and were peeled prior to freeze-drying. The freeze-dried fruits were turned into powder by using a commercial grinder. The powder was sieved using sieve number $60(250 \mu \mathrm{m})$ to achieve constant particle size. All samples were kept at $-20^{\circ} \mathrm{C}$ in amber bottle and kept until further analysis.

2.2.2. Extraction of Pigments. In the extraction procedure, $0.5 \mathrm{~g}$ of the fruit powder was mixed with various volumes of methanol acidified with $0.5 \%$ acetic acid or ethanol acidified with $0.5 \%$ acetic acid to give a solid to liquid ratio ranging from $0.5: 5$ to $0.5: 35(\mathrm{~g} / \mathrm{mL})$. Conical flask was used and covered with aluminium foil to prevent the evaporation
TABLE 1: Independent variables and their levels used for BoxBehnken design.

\begin{tabular}{lcccc}
\hline Variables & Factors & \multicolumn{3}{c}{ Levels } \\
& $X$ & -1 & 0 & 1 \\
\hline Extraction temperature, $\left({ }^{\circ} \mathrm{C}\right)$ & $X_{1}$ & 30 & 45 & 60 \\
Extraction time, $(\mathrm{min})$ & $X_{2}$ & 60 & 90 & 120 \\
Solid to liquid ratio, $(\mathrm{g} / \mathrm{mL})$ & $X_{3}$ & $0.5: 5$ & $0.5: 20$ & $0.5: 35$ \\
\hline
\end{tabular}

of solvent. The flask containing sample powder along with solvent was incubated in thermostatic water bath at various temperatures $\left(30-60^{\circ} \mathrm{C}\right)$ and various time intervals (60$120 \mathrm{~min})$. After extraction for a period of selected time, the mixture was centrifuged for $10 \mathrm{~min}$. The supernatant was then filtered and evaluated for the total anthocyanin content. Experiments were performed in randomized order to minimize the variability caused by nuisance factors. All the experiments were performed in triplicate and the average value was used for the determination of total anthocyanin content from M. malabathricum fruit.

2.2.3. Experimental Design. RSM was used to optimize the methanolic extraction and ethanolic extraction of anthocyanins from M. malabathricum fruit. A Box-Behnken design (BBD) was used in the optimization of process variables with three factors at three levels with 17 runs, including 5 central points (Table 1 ). The responses function $(Y)$ was partitioned into linear, quadratic, and interactive components. Experimental data were fitted to the second-order regression equation:

$$
\begin{aligned}
Y= & b_{0}+b_{1} X_{1}+b_{2} X_{2}+b_{3} X_{3}+b_{11} X_{1}^{2} \\
& +b_{22} X_{2}^{2}+b_{33} X_{3}^{2}+b_{12} X_{1} X_{2}+b_{13} X_{1} X_{3} \\
& +b_{23} X_{2} X_{3},
\end{aligned}
$$

where $b_{0}$ is the intercept; $b_{1}, b_{2}$, and $b_{3}$ are linear coefficients; $b_{11}, b_{22}$, and $b_{33}$ are squared coefficients; $b_{12}, b_{13}$, and $b_{23}$ are interaction coefficients.

The experimental design and statistical analysis were performed using Design-Expert software (version 8.0.7.1, Stat Ease Inc., Minneapolis, MN, USA). The model adequacies were checked in terms of the values of $R^{2}$ and adjusted $R^{2}$. Analysis of variance (ANOVA) was employed to determine the significance of the models. Verification of optimized conditions and predicted values were done in triplicate to confirm the validity of the models.

2.2.4. Total Anthocyanin Content Measurement. The total anthocyanin content was determined according to the spectrophotometric $\mathrm{pH}$ differential method [17]. Samples were diluted separately with $0.025 \mathrm{M}$ potassium chloride buffer ( $\mathrm{pH} 1)$ and $0.4 \mathrm{M}$ sodium acetate buffer ( $\mathrm{pH} 4.5)$. Absorbance of the mixture was measured at $511\left(\lambda_{\text {vis-max }}\right)$ and $700 \mathrm{~nm}$ using a UV-Vis spectrophotometer. Absorbance was calculated as $A=\left[\left(A_{511}-A_{700}\right) \mathrm{pH} 1.0-\left(A_{511}-A_{700}\right) \mathrm{pH} 4.5\right]$. 
The total anthocyanin content was calculated as cyanidin-3glucoside equivalents as in the following equation:

$$
\begin{aligned}
& \text { Anthocyanin content }(\mathrm{mg} / 100 \mathrm{~g}) \\
& =\frac{A \times \mathrm{MW} \times \mathrm{DF} \times V \times 100}{\varepsilon \times l \times m_{\text {sample }}},
\end{aligned}
$$

where $A$ is the absorbance, MW is the molecular weight of ( $449.2 \mathrm{~g} / \mathrm{mol}$ of cyanidin-3-glucoside), DF is the dilution factor, $V$ is the solvent volume $(\mathrm{mL})$ that was brought as sample stock solution, $\varepsilon$ is the molar absorptivity (26900), $l$ is the cell path length $(1 \mathrm{~cm})$, and $m$ is the freeze-dried sample weight ( $\mathrm{g})$.

2.2.5. Purification of Anthocyanin. The crude anthocyanin extract was concentrated by using a rotary evaporator $\left(40^{\circ} \mathrm{C}\right)$. The aqueous concentrates were then placed in a separating funnel and an equal volume of ethyl acetate was added to remove lipids, chlorophylls, and other nonpolar compounds from the mixture. The partitioned aqueous extract was further purified by using ion exchange chromatography (IEC) and size exclusion chromatography (SEC) using Amberlite XAD-7 resin and Sephadex LH-20 as separation matrixces, respectively. Anthocyanin content in the fractions collected using size exclusion chromatography was determined by $\mathrm{pH}$ differential method and fractions containing the highest content of anthocyanin were chosen for identification analyses.

2.2.6. Identification of Anthocyanin Using UPLC-ESI-MS/MS. Analytical ultra performance liquid chromatography (Perkin Elmer FX15) was used in this study. The anthocyanin fractions were then analyzed using AB Sciex 3200Q Trap, equipped with Phenomenex Aqua C18 reverse-phase column $(50 \mathrm{~mm} \times 2.0 \mathrm{~mm} \times 5 \mu \mathrm{M})$. Solvents were (A) water with $0.1 \%$ formic acid and $5 \mathrm{mM}$ ammonium formate and (B) acetonitrile with $0.1 \%$ formic acid and $5 \mathrm{mM}$ ammonium formate, establishing the following gradient: from $10 \% \mathrm{~B}$ to $90 \%$ B from $0.01 \mathrm{~min}$ to $8 \mathrm{~min}$, held for $3 \mathrm{~min}$ and back to $10 \% \mathrm{~A}$ in $0.1 \mathrm{~min}$ and reequilibrated for $5 \mathrm{~min}$. Samples were filtered with nylon $0.22 \mu \mathrm{M}$. The electrospray ionization (ESI) was operated in negative and positive ion modes under the following conditions: mass range between 100 and 1200; capillary voltages $+5500 \mathrm{~V}$ and $-4500 \mathrm{~V}$; nebulizer purified $\mathrm{N}_{2}$ gas, $40 \mathrm{psi}$, and source temperature $400^{\circ} \mathrm{C}$. Mass fragmentations were based on journal references and ACD/Labs advanced chemometrics mass fragmentation predictive software $[6,18]$.

\section{Results and Discussion}

3.1. Box-Behnken Analysis. In this study, BBD was used for response surface optimization with three process variables (extraction temperature, extraction time, and solid to liquid ratio) at three levels. Designs using BBD are usually very efficient in terms of the number of required runs and therefore are less expensive to run compared to central composite design (CCD). The design points fall within a safe operating limit, within the nominal high and low levels, as BBD does not contain any points at the vertices of the cubic region. This could be advantageous when the factor-level combinations are prohibitively expensive or impossible to test because of the physical process constraints [19].

Two different tests, namely, sequential model sum of squares and model summary statistic were performed to check the adequacy of the models generated from the obtained data and the results are given in Table 2. Model summary statistics output (Table 2) showed that, for methanolic extraction and ethanolic extraction, the values for the $R^{2}$ and adjusted $R^{2}$ were the highest compared the other models while the cubic model was disregarded as it is aliased. For quadratic versus 2FI (2 factor interaction), the $P$ value obtained was less than 0.0001 which shows strength of significance. The addition of the quadratic (squared) term to the mean, linear, and the two-factor interaction terms would only strengthen the model. With the exclusion of the cubic model, the Box-Behnken matrix has sufficient data to interpret the outcome of the present system [20].

3.2. Statistical Analysis for Selected Models. Summary of analysis of variance (ANOVA) for the selected quadratic polynomial model for methanolic extraction and ethanolic extraction was listed in Table 3. The ANOVA of quadratic regression model demonstrated that both models were highly significant, evident from Fisher's $F$-test with high $F$ value and low $P$ value. Lack-of-Fit is the variation due to the model inadequacy. The lack of fit was not significant for both models (Table 3). Therefore, there is no evidence to indicate that the models do not adequately explain the variation in the responses.

The coefficient of determination $\left(R^{2}\right)$ is defined as ratio of sum of squares due to regression to the total sum of squares and is interpreted as the proportion of the variability in the data explained by the ANOVA. The values of $R^{2}$ were 0.972 and 0.954 for methanolic extraction and ethanolic extraction, respectively (Table 2), which relatively high values which imply that more than $95 \%$ of experimental data can be explained by the model. The adjusted $R^{2}$ value corrects the $R^{2}$ value for the sample size and for the number of terms in the model [21]. The values of adjusted $R^{2}$ for methanolic and ethanolic extraction were 0.936 and 0.895 , respectively, which are also high and indicate a high correlation between the observed and the predicted values. Table 4 presents a Box-Behnken design with 17 experiments as well as the experimental $\left(Y_{\text {exp }}\right)$ and predicted response functions $\left(Y_{\text {pre }}\right)$ for both methanolic and ethanolic extractions.

As both models showed a satisfactory fit, normal probability plot of the residuals were generated to check the normality of the residuals (Figure 1). Studentized residual is the residual divided by an estimate of its standard deviation. The residuals were studentized and values which were greater than +2 and less than -2 were considered as large. Obtaining a smaller residual value is preferred as this shows the degree of deviancy from predicted model. It is clear from Figure 1 that the residuals followed normal distribution well as majority of the data points followed the fitted line fairly closely with no reasonable outliers. 
TABLE 2: Adequecy of model tested.

\begin{tabular}{|c|c|c|c|c|c|c|}
\hline Source & Sum of squares & $\mathrm{df}$ & Mean square & $F$ Value & Prob $>F$ & Remarks \\
\hline \multicolumn{7}{|c|}{ Sequential model sum of squares for acidified methanolic extraction } \\
\hline Mean versus Total & 20893255.04 & 1 & 20893255.04 & & & \\
\hline Linear versus Mean & 128877.78 & 3 & 42959.26 & 20.25 & $<0.0001$ & \\
\hline 2FI versus Linear & 10748.42 & 3 & 3582.81 & 2.13 & 0.1600 & \\
\hline Quadratic versus 2FI & 12433.06 & 3 & 4144.35 & 6.60 & 0.0189 & Suggested \\
\hline Cubic versus Quadratic & 874.80 & 3 & 291.60 & 0.33 & 0.8045 & Aliased \\
\hline Residual & 3520.73 & 4 & 880.18 & & & \\
\hline Total & 21049709.83 & 17 & 1238218.23 & & & \\
\hline \multicolumn{7}{|c|}{ Sequential model sum of squares for acidified ethanolic extraction } \\
\hline Mean versus Total & 7196887.80 & 1 & 7196887.80 & & & \\
\hline Linear versus Mean & 147605.80 & 3 & 49201.93 & 28.80 & $<0.0001$ & Suggested \\
\hline 2FI versus Linear & 532.96 & 3 & 177.65 & 0.08 & 0.9683 & \\
\hline Quadratic versus 2FI & 13908.91 & 3 & 4636.30 & 4.18 & 0.0544 & Suggested \\
\hline Cubic versus Quadratic & 6069.16 & 3 & 2023.05 & 4.76 & 0.0829 & Aliased \\
\hline Residual & 1699.43 & 4 & 424.86 & & & \\
\hline Total & 7366704.07 & 17 & 433335.53 & & & \\
\hline Source & Std. Dev. & $R^{2}$ & Adjusted $R^{2}$ & Predicted $R^{2}$ & PRESS & Remarks \\
\hline \multicolumn{7}{|c|}{ Model summary statistics for acidified methanolic extraction } \\
\hline Linear & 46.058 & 0.824 & 0.783 & 0.654 & 54157.757 & \\
\hline $2 \mathrm{FI}$ & 41.023 & 0.892 & 0.828 & 0.542 & 71629.308 & \\
\hline Quadratic & 25.059 & 0.972 & 0.936 & 0.875 & 19498.004 & Suggested \\
\hline Cubic & 29.668 & 0.977 & 0.910 & & + & Aliased \\
\hline \multicolumn{7}{|c|}{ Model summary statistics for acidified ethanolic extraction } \\
\hline Linear & 41.334 & 0.869 & 0.839 & 0.741 & 43972.027 & Suggested \\
\hline $2 \mathrm{FI}$ & 46.559 & 0.872 & 0.796 & 0.406 & 100897.766 & \\
\hline Quadratic & 33.314 & 0.954 & 0.895 & 0.413 & 99761.992 & Suggested \\
\hline Cubic & 20.612 & 0.990 & 0.960 & & + & Aliased \\
\hline
\end{tabular}

+ Case(s) with leverage of 1.0000: PRESS statistic not defined.

3.3. Effect of Extraction Temperature, Time, and Solid to Liquid Ratio on Anthocyanin Yield. The significance of each coefficient was determined by Fisher's $F$-test and $P$ value, and the larger the magnitude of $F$-value and the smaller the $P$-value, the more significant are the corresponding coefficient is. Data in Table 3 showed that, for methanolic extraction, all linear components in the experimental model were significant $(P<0.05)$ with temperature having the strongest effect on anthocyanin yield followed by solid to liquid ratio and extraction time. Positive coefficient indicated a linear effect to increase $Y$ whereas negative coefficient indicated a linear effect to decrease $Y$.

For methanolic extraction, the anthocyanin yield can be increased with the increase of extraction temperature as shown in Figure 2(a). The positive linear effect $(P<0.01)$ and significant negative quadratic effect $(P<0.05)$ of time have resulted in a curvilinear increase in anthocyanin yield for all the extraction time. It could be seen in Figures 2(a) and 2(c) that an increase of time beyond a certain limit of the tested range has resulted in the increase of the anthocyanin yield. As temperature and solid to liquid ratio have a stronger effect compared to time for methanolic extraction, excessive extraction time might not be effective for the extraction process. Long exposure at high temperatures would be detrimental to the desired compound as it would undergo the process of oxidation and polymerization. In addition, from an industrial point of view, longer extraction time means lower efficiency of equipment utilization [2]. Figure 2(b) showed that the increase of anthocyanin yield caused by temperature and solid to liquid ratio was almost linear. Therefore, at a fixed extraction time and by increasing the extraction temperature the result was as good as increasing the solid to liquid ratio.

Table 3 showed that, for ethanolic extraction, the extraction temperature and time play an important role in determining anthocyanin yield. The effects of extraction temperature and time on anthocyanin yield are shown in Figure 2(d). Because both of the variables played more prominent role in the extraction efficiency for ethanolic extraction, by increasing temperature and time, the total anthocyanin content increases significantly. By heating, it gives energy to the molecules in the system to vibrate thus weakening the bond between compounds, disrupting cell membrane, and causing the compound in the cell compartment to spill out into the solvent. Figures 2(e) and 2(f) showed that the increasing of time and temperature increase anthocyanin yield with the increasing of the solid to liquid ratio up to 
TABLE 3: ANOVA for response surface quadratic model.

\begin{tabular}{|c|c|c|c|c|c|c|c|}
\hline Source & Coefficient estimate & Sum of squares & $\mathrm{df}$ & Mean square & $F$-value & $P$-value & Remarks \\
\hline \multicolumn{8}{|c|}{ Acidified methanolic extraction } \\
\hline Model & 1114.595 & 152059.256 & 9 & 16895.473 & 26.906 & 0.0001 & Significant \\
\hline$X_{1}$ & 103.359 & 85464.893 & 1 & 85464.893 & 136.105 & $<0.0001$ & \\
\hline$X_{2}$ & 26.475 & 5607.274 & 1 & 5607.274 & 8.930 & 0.0203 & \\
\hline$X_{3}$ & 68.744 & 37805.617 & 1 & 37805.617 & 60.206 & 0.0001 & \\
\hline$X_{12}$ & -45.922 & 8435.296 & 1 & 8435.296 & 13.433 & 0.0080 & \\
\hline$X_{13}$ & 22.196 & 1970.579 & 1 & 1970.579 & 3.138 & 0.1198 & \\
\hline$X_{23}$ & 9.254 & 342.543 & 1 & 342.543 & 0.546 & 0.4842 & \\
\hline$X_{1}{ }^{2}$ & 24.728 & 2574.683 & 1 & 2574.683 & 4.100 & 0.0825 & \\
\hline$X_{2}^{2}$ & -48.608 & 9948.234 & 1 & 9948.234 & 15.843 & 0.0053 & \\
\hline$X_{3}{ }^{2}$ & 11.160 & 524.442 & 1 & 524.442 & 0.835 & 0.3912 & \\
\hline Residual & & 4395.537 & 7 & 627.934 & & & \\
\hline Lack of fit & & 874.804 & 3 & 291.601 & 0.331 & 0.8045 & Not significant \\
\hline Pure error & & 3520.733 & 4 & 880.183 & & & \\
\hline Cor total & & 156454.793 & 16 & & & & \\
\hline \multicolumn{8}{|c|}{ Acidified ethanolic extraction } \\
\hline Model & 664.170 & 162047.676 & 9 & 18005.297 & 16.224 & 0.0007 & Significant \\
\hline$X_{1}$ & 118.806 & 112918.450 & 1 & 112918.450 & 101.747 & $<0.0001$ & \\
\hline$X_{2}$ & 57.681 & 26616.436 & 1 & 26616.436 & 23.983 & 0.0018 & \\
\hline$X_{3}$ & 31.763 & 8070.915 & 1 & 8070.915 & 7.272 & 0.0308 & \\
\hline$X_{12}$ & 7.237 & 209.468 & 1 & 209.468 & 0.189 & 0.6770 & \\
\hline$X_{13}$ & -3.966 & 62.917 & 1 & 62.917 & 0.057 & 0.8186 & \\
\hline$X_{23}$ & -8.071 & 260.580 & 1 & 260.580 & 0.235 & 0.6428 & \\
\hline$X_{1}^{2}$ & 31.220 & 4103.958 & 1 & 4103.958 & 3.698 & 0.0959 & \\
\hline$X_{2}^{2}$ & -11.849 & 591.175 & 1 & 591.175 & 0.533 & 0.4892 & \\
\hline$X_{3}{ }^{2}$ & -48.100 & 9741.404 & 1 & 9741.404 & 8.778 & 0.0210 & \\
\hline Residual & & 7768.593 & 7 & 1109.799 & & & \\
\hline Lack of fit & & 6069.165 & 3 & 2023.055 & 4.762 & 0.0829 & Not significant \\
\hline Pure error & & 1699.428 & 4 & 424.857 & & & \\
\hline Cor total & & 169816.269 & 16 & & & & \\
\hline
\end{tabular}

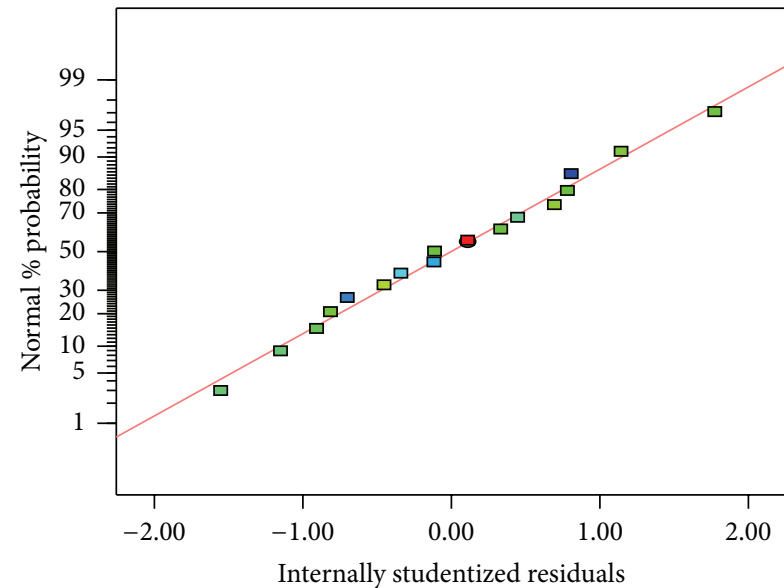

(a)

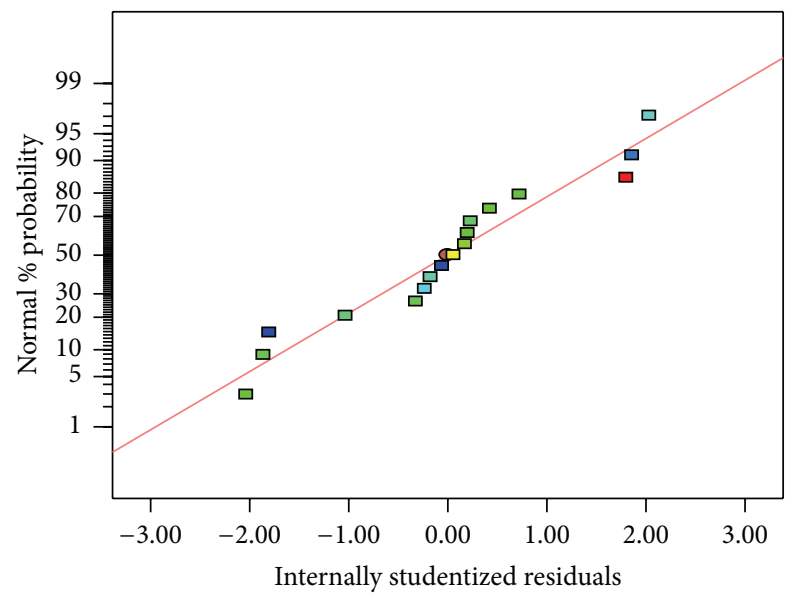

(b)

FIGURE 1: Normal probability plots of residuals for (a) methanolic extraction and (b) ethanolic extraction. 


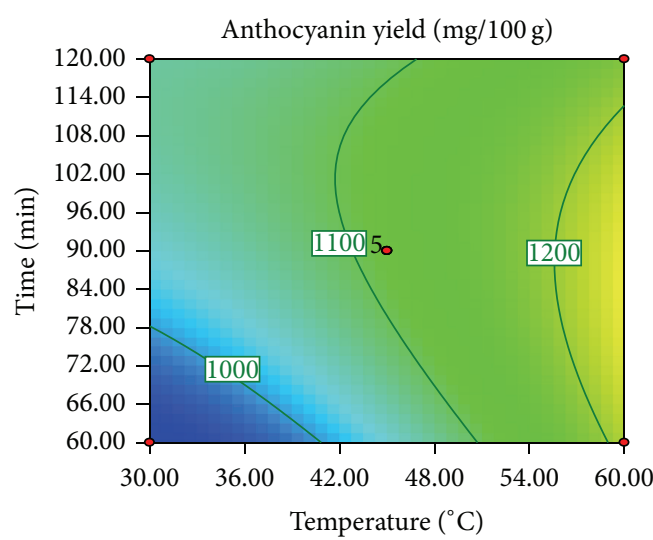

(a)

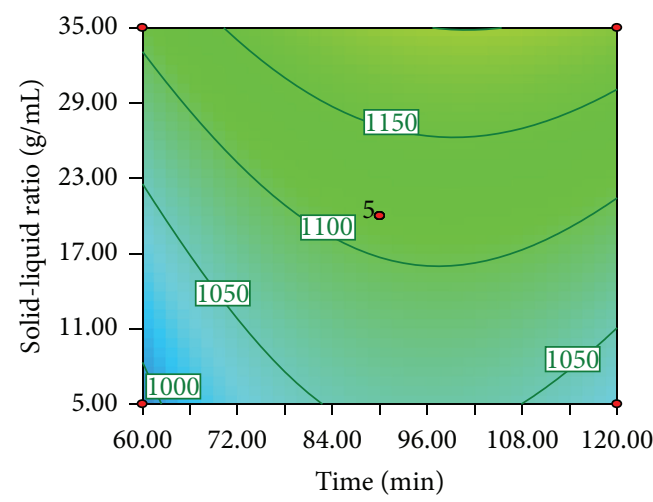

(c)

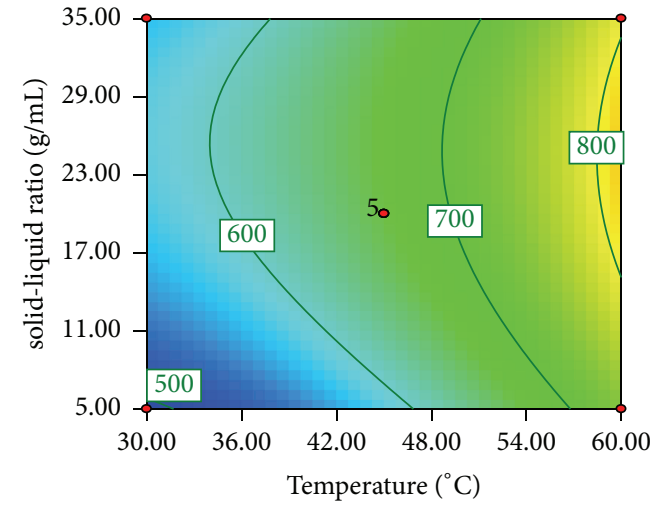

(e)

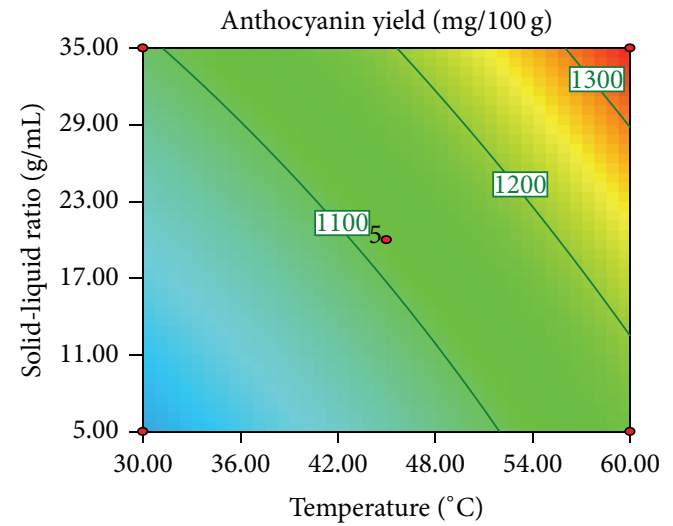

(b)

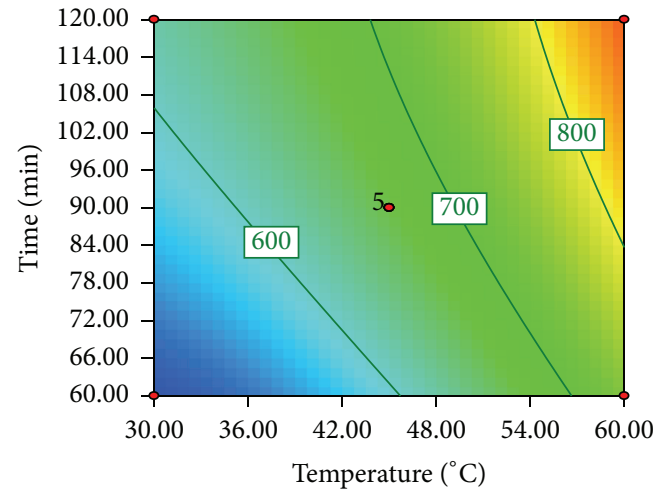

(d)

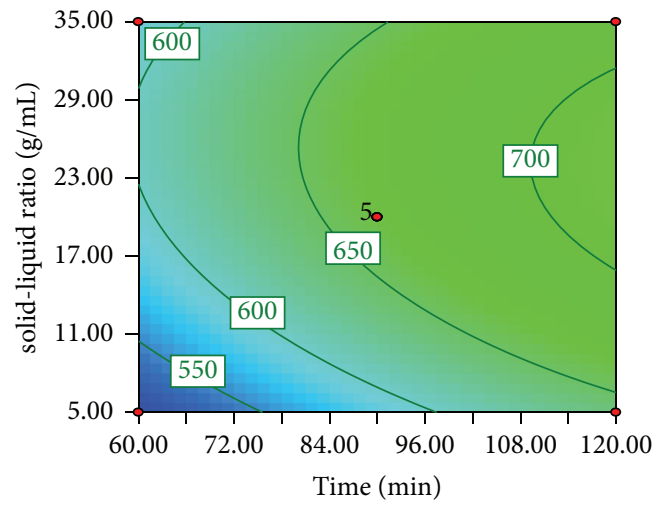

(f)

FIGURE 2: Contour plot showing the effects of variables for $(a-c)$ methanolic extraction and (d-f) ethanolic extraction.

a certain limit of the tested range. However, further increases of solid to liquid ratio did not translate into significant improvement in the yield. This can be seen in Table 3; the values of positive linear effect and negative quadratic effect of solid to liquid ratio are significant $(P<0.05)$. This observation can be explained by the fact that the system has become saturated as the solute has entirely dissolved in the fluid.

3.4. Perturbation Plot. Pertubation plot shows how a function of a certain factor responded as the level of that factor changes, when the other factors are fixed at their optimum levels [22]. A steep slope or curvature in the plots indicates the sensitivity of the response factor [23]. Pertubation plot for methanolic and ethanolic (Figures 3(a) and 3(b), resp.) extractions were used to assess the effect of each factor on the yield. For the methanolic extraction, identical anthocyanin yield increment was observed as the temperature and solid to liquid ratio factors were increased while the yield decreases as the extraction time factor was increased. This shows that, for methanolic extraction, factors such temperature and solid to liquid ratio would influence the amount of anthocyanin extracted. For ethanolic extraction, by comparing the slope 
TABLE 4: Box-Behnken design arrangement and responses.

\begin{tabular}{|c|c|c|c|c|c|c|c|c|c|}
\hline \multirow[t]{2}{*}{ Run } & \multirow[t]{2}{*}{$X_{1}$} & \multirow[t]{2}{*}{$X_{2}$} & \multirow[t]{2}{*}{$X_{3}$} & \multicolumn{3}{|c|}{$\begin{array}{l}\text { Anthocyanin yield* (mg/100 g) } \\
\text { (acidified methanolic extraction) }\end{array}$} & \multicolumn{3}{|c|}{$\begin{array}{l}\text { Anthocyanin yield* }(\mathrm{mg} / 100 \mathrm{~g} \text { ) } \\
\text { (acidified ethanolic extraction) }\end{array}$} \\
\hline & & & & $Y_{\exp }$ & $Y_{\text {pre }}$ & $\%$ sd & $Y_{\exp }$ & $Y_{\text {pre }}$ & $\%$ sd \\
\hline 1 & 45 & 90 & 20 & 1132.18 & 1114.60 & 3.40 & 654.60 & 664.17 & 2.65 \\
\hline 2 & 60 & 120 & 20 & 1164.47 & 1110.16 & 1.32 & 897.29 & 867.26 & 3.46 \\
\hline 3 & 30 & 60 & 20 & 925.12 & 1114.60 & 1.10 & 484.27 & 514.29 & 8.36 \\
\hline 4 & 45 & 90 & 20 & 1154.45 & 1114.60 & 2.84 & 633.44 & 664.17 & 1.85 \\
\hline 5 & 45 & 60 & 5 & 982.45 & 1114.60 & 2.75 & 537.70 & 506.71 & 2.19 \\
\hline 6 & 45 & 90 & 20 & 1094.33 & 1000.58 & 1.74 & 685.77 & 664.17 & 3.13 \\
\hline 7 & 30 & 120 & 20 & 1065.39 & 1213.52 & 4.05 & 612.29 & 615.18 & 4.41 \\
\hline 8 & 45 & 120 & 5 & 1021.42 & 1025.63 & 3.10 & 642.07 & 638.21 & 2.08 \\
\hline 9 & 45 & 90 & 20 & 1079.86 & 1162.90 & 4.65 & 676.86 & 664.17 & 4.25 \\
\hline 10 & 60 & 90 & 5 & 1177.27 & 914.96 & 2.87 & 704.42 & 738.30 & 3.95 \\
\hline 11 & 45 & 120 & 35 & 1190.35 & 1181.62 & 4.29 & 654.60 & 685.59 & 1.79 \\
\hline 12 & 45 & 60 & 35 & 1114.37 & 991.18 & 4.28 & 582.51 & 586.38 & 7.79 \\
\hline 13 & 30 & 90 & 5 & 999.15 & 1344.78 & 2.65 & 491.78 & 492.76 & 1.18 \\
\hline 14 & 60 & 60 & 20 & 1207.89 & 1114.60 & 3.10 & 740.32 & 737.43 & 9.90 \\
\hline 15 & 30 & 90 & 35 & 1079.31 & 1093.67 & 7.93 & 598.10 & 564.21 & 8.31 \\
\hline 16 & 60 & 90 & 35 & 1346.21 & 1059.75 & 5.70 & 794.87 & 793.89 & 0.00 \\
\hline 17 & 45 & 90 & 20 & 1112.15 & 1174.63 & 3.16 & 670.18 & 664.17 & 3.32 \\
\hline
\end{tabular}

${ }^{*}$ Data are presented as mean of triplicate analyses.

$X_{1}$ : temperature; $X_{2}$ : time; $X_{3}$ : solid-liquid ratio.

$\%$ sd $<10$ is considered significant.

TABLE 5: Experiment confirmation of predicted value at optimal extraction condition.

\begin{tabular}{|c|c|c|c|c|c|c|}
\hline \multirow{3}{*}{ Optimal levels } & \multicolumn{6}{|c|}{ Anthocyanin yield $(\mathrm{mg} / 100 \mathrm{~g})$} \\
\hline & \multirow{2}{*}{$Y_{\text {predicted }}$} & \multicolumn{3}{|c|}{ Experimental value } & \multirow{2}{*}{ Mean* } & \multirow{2}{*}{ Relative error $^{\mathrm{a}}(\%)$} \\
\hline & & 1 & 2 & 3 & & \\
\hline Acidified methanolic extraction & 1345.320 & 1297.503 & 1437.774 & 1303.348 & 1346.208 & 0.066 \\
\hline \multicolumn{7}{|l|}{$X_{1}=60^{\circ} \mathrm{C}$} \\
\hline \multicolumn{7}{|l|}{$X_{2}=120 \mathrm{~min}$} \\
\hline \multicolumn{7}{|l|}{$X_{3}=0.5 \mathrm{~g}: 23.1 \mathrm{~mL}$} \\
\hline Acidified ethanolic extraction & 869.290 & 878.355 & 886.060 & 878.355 & 880.923 & 1.321 \\
\hline \multicolumn{7}{|l|}{$X_{1}=60^{\circ} \mathrm{C}$} \\
\hline \multicolumn{7}{|l|}{$X_{2}=86.89 \mathrm{~min}$} \\
\hline$X_{3}=0.5 \mathrm{~g}: 35 \mathrm{~mL}$ & & & & & & \\
\hline
\end{tabular}

${ }^{a}$ Relative error $(\%)=[($ experimental value - predicted value $) /$ experimental value $] \times 100 \%$.

Mean is average value from triplicate of experimental run.

of every factor, it was seen that temperature is dominant compared to time in terms of the influence it had on anthocyanin yield. For solid to liquid ratio, it plays a minimal influence on anthocyanin yield.

3.5. Verification of Optimized Condition and Predictive Model. Optimization of anthocyanin extraction from M. malabathricum fruit was performed by using numerical optimization. The Design-Expert software used searches for a combination of factor levels that simultaneously satisfy the requirements placed on each of the responses and factors. Optimization requires that goals (i.e., none, maximum, minimum, target, or in range) are set for the variables and response where all goals then get combined into one desirability function. To find a good set of conditions that will meet all the goals, the three variables (i) extraction temperature $\left(30^{\circ} \mathrm{C}-\right.$ $60^{\circ} \mathrm{C}$ ), (ii) extraction time $(60-120 \mathrm{~min}$ ), and (iii) solid to liquid ratio $(\mathrm{g} / \mathrm{mL})$ were set within range while anthocyanin yield was set at maximum. The "importance" of goals (option 1-5) for all variables was considered to be equally important in a setting of 3 . For response, the "importance" was set at 5 in order to meet the objective of getting maximum anthocyanin yield. By applying the desirability function approach, the optimum level of various parameters was obtained as showed in Table 5. Figure 4 showed desirability ramps that were developed from optimum points via numerical optimization. 


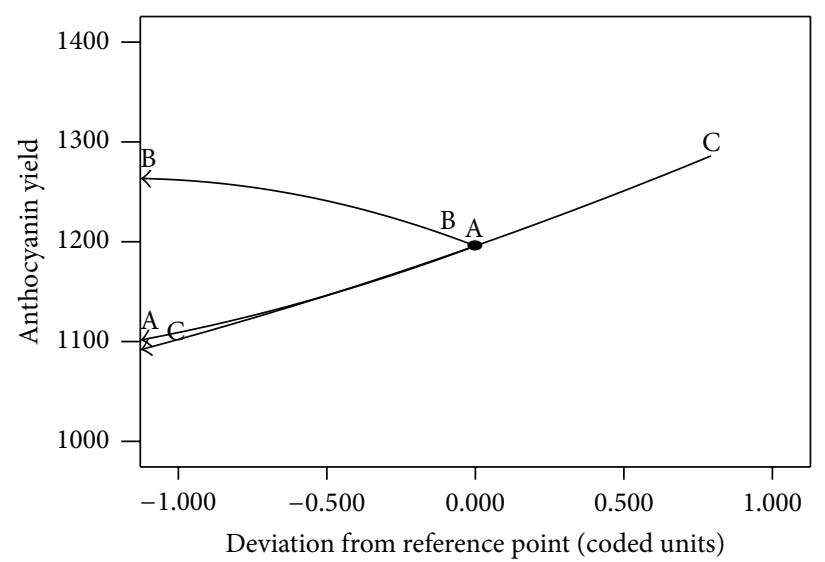

(a)

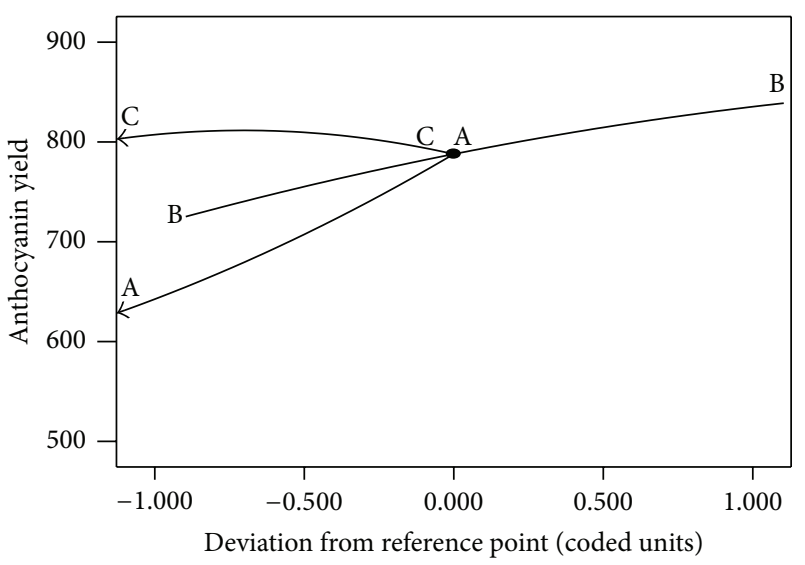

(b)

Figure 3: Perturbation plots for (a) methanolic extraction at temperature $60^{\circ} \mathrm{C}$; time $120 \mathrm{~min}$; solid to liquid ratio $23.1 \mathrm{~g} / \mathrm{mL}$ and (b) ethanolic extraction at temperature $60^{\circ} \mathrm{C}$; time $86.89 \mathrm{~min}$; solid to liquid ratio $35 \mathrm{~g} / \mathrm{mL}$.

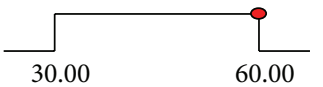

A: temperature $=60.00$

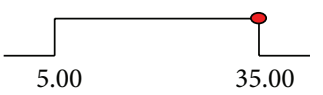

C: solid-liquid ratio $=35.00$

Desirability $=0.998$
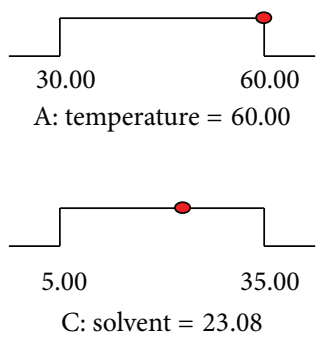

Desirability $=0.932$
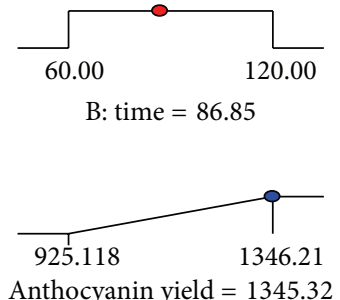

(a)
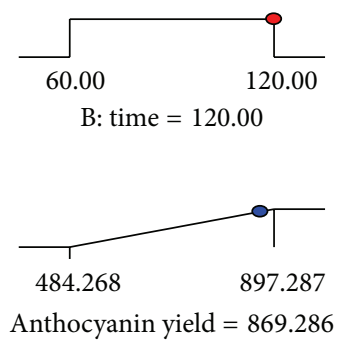

(b)

Figure 4: Desirability ramp of optimization for (a) methanolic extraction and (b) ethanolic extraction.

A triplicate experiment was set up to validate the optimized condition. As shown in Table 5, the experimental data were in good agreement with the predicted values for methanolic and ethanolic extractions. Relative error between predicted and experimental values fell at $0.066 \%$ ( $1346.208 \mathrm{mg} / 100 \mathrm{~g}$ ) and $1.321 \%$ ( $880.923 \mathrm{mg} / 100 \mathrm{~g})$ for methanolic and ethanolic extractions, respectively. The verification value for anthocyanin yield obtained is within 99\% of predicted values which clearly showed that the model fitted the experimental data very well and therefore optimized the anthocyanin extraction efficiently within the specified range of process parameters.

3.6. Identification of Anthocyanin. Figure 5 showed the mass spectra for (Figures 5(a)-5(c)) positive mode and (Figures 5(d)-5(e)) negative mode of anthocyanin-rich extract of $M$. malabathricum by UPLC-ESI-MS/MS. Figure 5(a) (retention time $t_{R}=0.763 \mathrm{~min}$ ), with $M^{+}$at $m / z 611.3$, was identified as cyanidin dihexoside and fragments ions at $m / z 449.1$ and $\mathrm{m} / z 287.2$ corresponded to cyanidin. Figure $5(\mathrm{~b})\left(t_{R}=\right.$ $2.841 \mathrm{~min}$ ), with $M^{+}$at $m / z 449.1$, was identified as cyanidin hexoside and fragment ions at $m / z$ 287.2. Figure 5(c) $\left(t_{R}=\right.$ $2.950 \mathrm{~min}$ ), with $M^{+}$at $m / z 287.2$, was identified as cyanidin aglycone. Figure $5(\mathrm{~d})\left(t_{R}=0.762 \mathrm{~min}\right)$, with $M^{-}$at $\mathrm{m} / z$ 627.2, was identified as delphinidin dihexoside and fragments ions at $m / z 465.1$ and $m / z 303.1$ corresponded to delphinidin. Figure $5(\mathrm{e})\left(t_{R}=2.510 \mathrm{~min}\right)$, with $M^{-}$at $\mathrm{m} / z$ 465.1, was identified as delphinidin hexoside and fragment ions at $\mathrm{m} / z$ 303.1.

\section{Conclusion}

The experimental design approach using RSM was successfully applied in the optimization of anthocyanins from $M$. malabathricum fruit. Under optimum condition, methanolic extraction showed the highest anthocyanin yield which was $1345.32 \mathrm{mg} / 100 \mathrm{~g}$ compared to ethanolic extraction, $869.29 \mathrm{mg} / 100 \mathrm{~g}$. By using the optimum condition established, anthocyanin pigments from methanolic extraction can be applied as natural colourants in coating products, textiles, and solar cell industry whereas anthocyanin pigments from ethanolic extraction are recommended for food applications due to thier GRAS (generally recognized as safe) qualification. In this study, among three parameters tested, temperature was found to be the most prominent factor affecting the efficiency of anthocyanin extraction. $M$. malabathricum fruit was tentatively identified to contain 


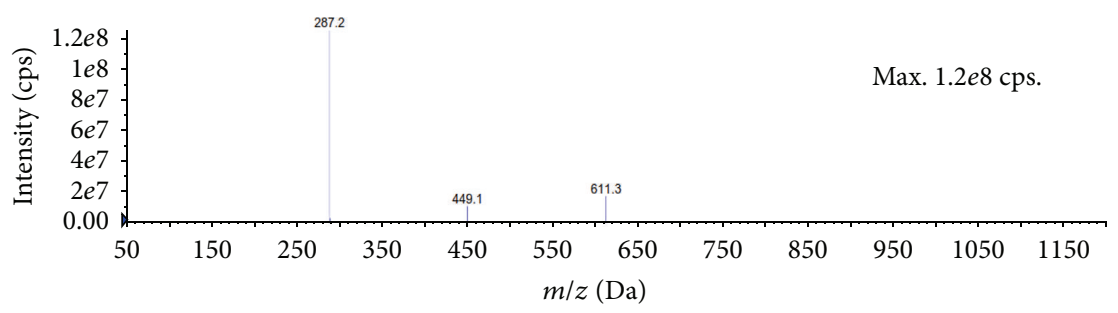

+EPI (611.33) charge (+1) CE (35) CES (15) FT (50): exp 2, 0.763 min from sample 1 (10-1) of 10.wiff (turbo spray), centroided

(a)

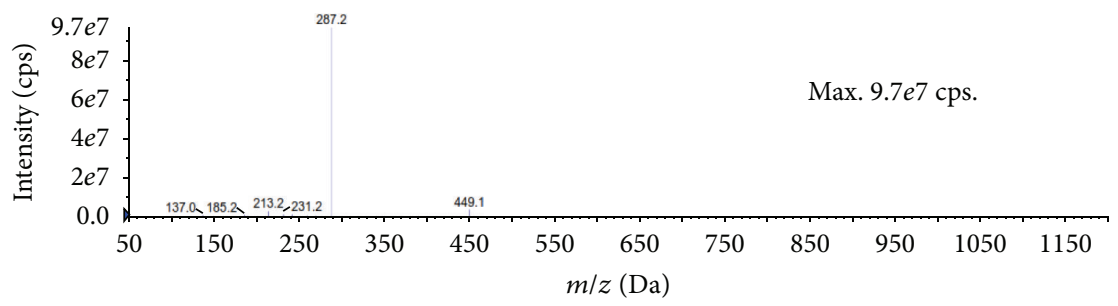

$\square$ +EPI (449.20) charge (+1) CE (35) CES (15) FT (50): exp 2, 2.841 min from sample 1 (10-1) of 10.wiff (turbo spray), centroided

(b)

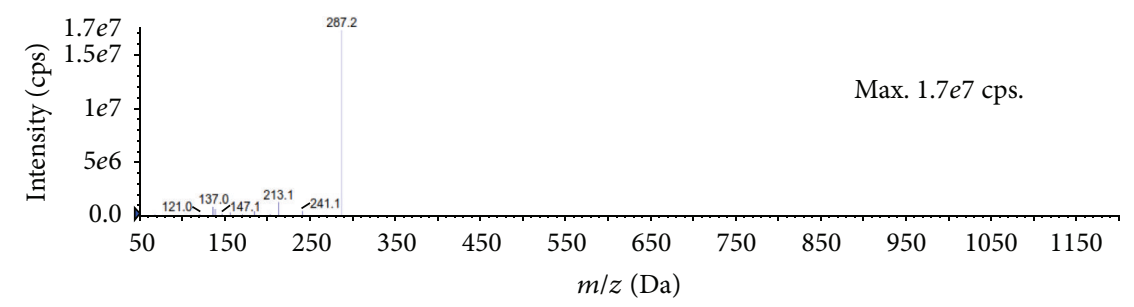

+EPI (287.37) charge (+1) CE (35) CES (15) FT (50): exp 2, 2.950 min from sample 1 (10-1) of 10.wiff (turbo spray), centroided

(c)

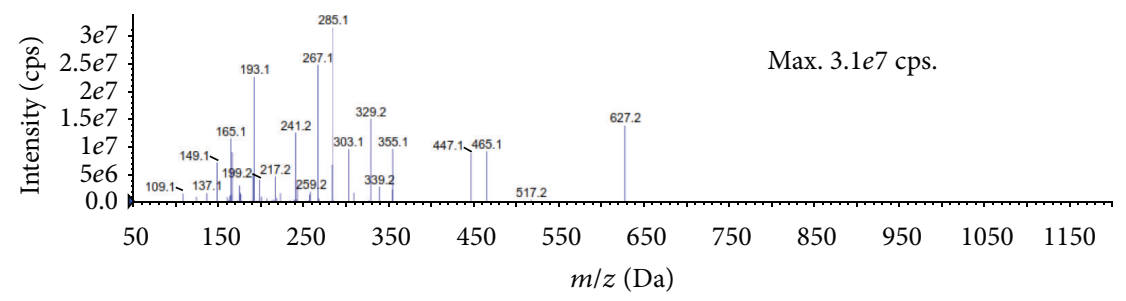

-EPI (627.42) charge (+1) FT (50): exp 2, 0.762 min from sample 4

(Neg 10-1) of 10.wiff (turbo spray), centroided

(d)

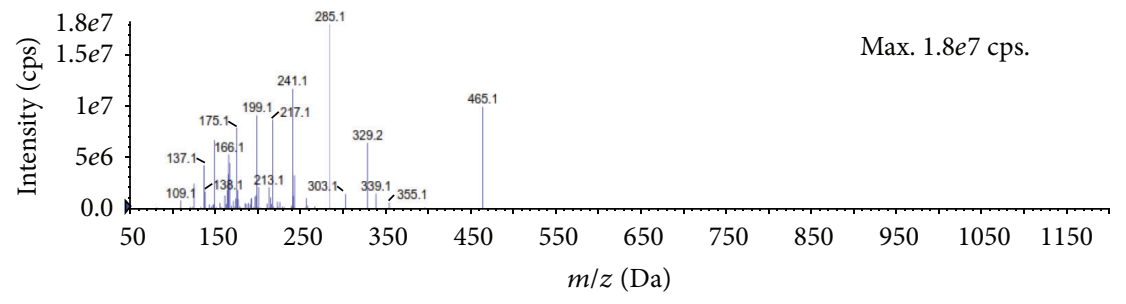

-EPI (465.22) charge (+1) FT (50): $\exp 2,2.510$ min from sample 4

(Neg 10-1) of 10.wiff (turbo spray), centroided

(e)

FIGURE 5: Mass spectra of anthocyanin-rich extract after gel filtration using Sephadex LH-20: (a-c) positive mode and (d-e) negative mode. 
cyanidin dihexoside, cyanidin hexoside, cyanidin, delphinidin dihexoside, and delphinidin hexoside.

\author{
Abbreviations \\ RSM: $\quad$ Response surface methodology \\ UPLC-ESI-MS/MS: Ultra performance liquid \\ chromatography electrospray tandem \\ mass spectrometry \\ BBD: \\ Box-Behnken design.
}

\section{Acknowledgments}

The authors gratefully acknowledge The Institute of Research Management and Monitoring (IPPP), University of Malaya, Kuala Lumpur, Malaysia, for the research Grants PV082/2012A, BK024-2011A, and RP003B-13AFR and The Institute of Biological Sciences, Faculty of Science, University of Malaya, Kuala Lumpur, Malaysia, for providing the facilities to carry out this research.

\section{References}

[1] T. A. Holton and E. C. Cornish, "Genetics and biochemistry of anthocyanin biosynthesis," Plant Cell, vol. 7, no. 7, pp. 1071-1083, 1995.

[2] J. Shi, J. Yu, J. Pohorly, J. C. Young, M. Bryan, and Y. Wu, "Optimization of the extraction of polyphenols from grape seed meal by aqueous ethanol solution," Food, Agriculture \& Environment, vol. 1, no. 2, pp. 42-47, 2003.

[3] K. A. Aduloju, M. B. Shitta, and S. Justus, "Effect of extracting solvents on the stability and performances of dye-sensitized solar cell prepared using extract from Lawsonia Inermis," Fundamental Journal Modern Physics, vol. 1, no. 2, pp. 261-268, 2011.

[4] N. M. Gómez-Ortíz, I. A. Vázquez-Maldonado, A. R. PérezEspadas, G. J. Mena-Rejón, J. A. Azamar-Barrios, and G. Oskam, "Dye-sensitized solar cells with natural dyes extracted from achiote seeds," Solar Energy Materials and Solar Cells, vol. 94, no. 1, pp. 40-44, 2010.

[5] N. Aziz, N. A. Mat Nor, A. F. Mohd-Adnan, R. M. Taha, and A. K. Arof, "Study of anthocyanin stability derived from the fruit pulp of Melastoma malabathricum in a coating system," Pigment \& Resin Technology, vol. 41, no. 4, pp. 223-2229, 2012.

[6] E. É. Nicoué, S. Savard, and K. Belkacemi, "Anthocyanins in wild blueberries of Quebec: extraction and identification," Journal of Agricultural and Food Chemistry, vol. 55, no. 14, pp. 5626-5635, 2007.

[7] H. M. Sirat, D. Susanti, F. Ahmad, H. Takayama, and M. Kitajima, "Amides, triterpene and flavonoids from the leaves of Melastoma malabathricum L," Journal of Natural Medicines, vol. 64, no. 4, pp. 492-495, 2010.

[8] D. X. Hou, T. Ose, S. Lin et al., "Anthocyanidins induce apoptosis in human promyelocytic leukemia cells: structureactivity relationship and mechanisms involved," International Journal of Oncology, vol. 23, no. 3, pp. 705-712, 2003.

[9] K.-T. Kim, T.-K. Nam, Y.-S. Park, Y.-B. Kim, and S.-W. Park, "Neuroprotective effect of anthocyanin on experimental traumatic spinal cord injury," Journal of Korean Neurosurgical Society, vol. 49, no. 4, pp. 205-211, 2011.
[10] Y. Yang, Z. Shi, A. Reheman, J. W. Jin, and C. Li, "Plant food delphinidin-3-glucoside significantly inhibits platelet activation and thrombosis: novel protective roles against cardiovascular diseases," PLoS ONE, vol. 7, no. 5, 2012.

[11] W. Wong, Melastoma malabathricum: Too Beautiful To Be Called A Weed, Green Culture, 2008, http://www.greenculturesg.com/articles/july08/july08_melastomam.pdf.

[12] S. M. Joffry, N. J. Yob, M. S. Rofiee et al., "Melastoma malabathricum (L.) smith ethnomedicinal uses, chemical constituents, and pharmacological properties: a review," Evidencebased Complementary and Alternative Medicine, vol. 2012, Article ID 258434, 48 pages, 2012.

[13] C. L. Ringmichon, S. N. Shimpi, and B. Gopalkrishnan, "Ethnomedicinal investigation on Melastoma malabathricum Linn. from Manipur," Journal of Herbal Medicine and Toxicology, vol. 4, no. 2, pp. 141-144, 2010.

[14] H. M. Sirat, D. Susanti, F. Ahmad, H. Takayama, and M. Kitajima, "Amides, triterpene and flavonoids from the leaves of Melastoma malabathricum L," Journal of Natural Medicines, vol. 64, no. 4, pp. 492-495, 2010.

[15] G. D. S. C. Borges, F. G. K. Vieira, C. Copetti, L. V. Gonzaga, and R. Fett, "Optimization of the extraction of flavanols and anthocyanins from the fruit pulp of Euterpe edulis using the response surface methodology," Food Research International, vol. 44, no. 3, pp. 708-715, 2011.

[16] H. H. Wijngaard and N. Brunton, "The optimisation of solid-liquid extraction of antioxidants from apple pomace by response surface methodology," Journal of Food Engineering, vol. 96, no. 1, pp. 134-140, 2010.

[17] J. Lee, R. W. Durst, and R. E. Wrolstad, "Determination of total monomeric anthocyanin pigment content of fruit juices, beverages, natural colorants, and wines by the $\mathrm{pH}$ differential method: collaborative study," Journal of AOAC International, vol. 88, no. 5, pp. 1269-1278, 2005.

[18] F. Lopes-Da-Silva, S. De Pascual-Teresa, J. Rivas-Gonzalo, and C. Santos-Buelga, "Identification of anthocyanin pigments in strawberry (cv Camarosa) by LC using DAD and ESI-MS detection," European Food Research and Technology, vol. 214, no. 3, pp. 248-253, 2002.

[19] D. C. Montgomery, Design and Analysis of Experiments, Jon Wiley \& Sons, New York, NY, USA, 2009.

[20] A. Kumar, B. Prasad, and I. M. Mishra, "Optimization of process parameters for acrylonitrile removal by a low-cost adsorbent using Box-Behnken design," Journal of Hazardous Materials, vol. 150, no. 1, pp. 174-182, 2008.

[21] J. P. Maran and S. Manikandan, "Response surface modeling and optimization of process parameters for aqueous extraction of pigments from prickly pear (Opuntia ficus-indica) fruit," Dyes and Pigments, vol. 95, no. 3, pp. 465-472, 2012.

[22] S. Oh, S. Rheem, J. Sim, S. Kim, and Y. Baek, "Optimizing conditions for the growth of Lactobacillus casei YIT 9018 in tryptone-yeast extract-glucose medium by using response surface methodology," Applied and Environmental Microbiology, vol. 61, no. 11, pp. 3809-3814, 1995.

[23] M. J. Anderson and P. J. Whitcomb, RSM Simplified: Optimizing Processes Using Response Surface Methods For Design of Experiments, Productivity Press, 2005. 

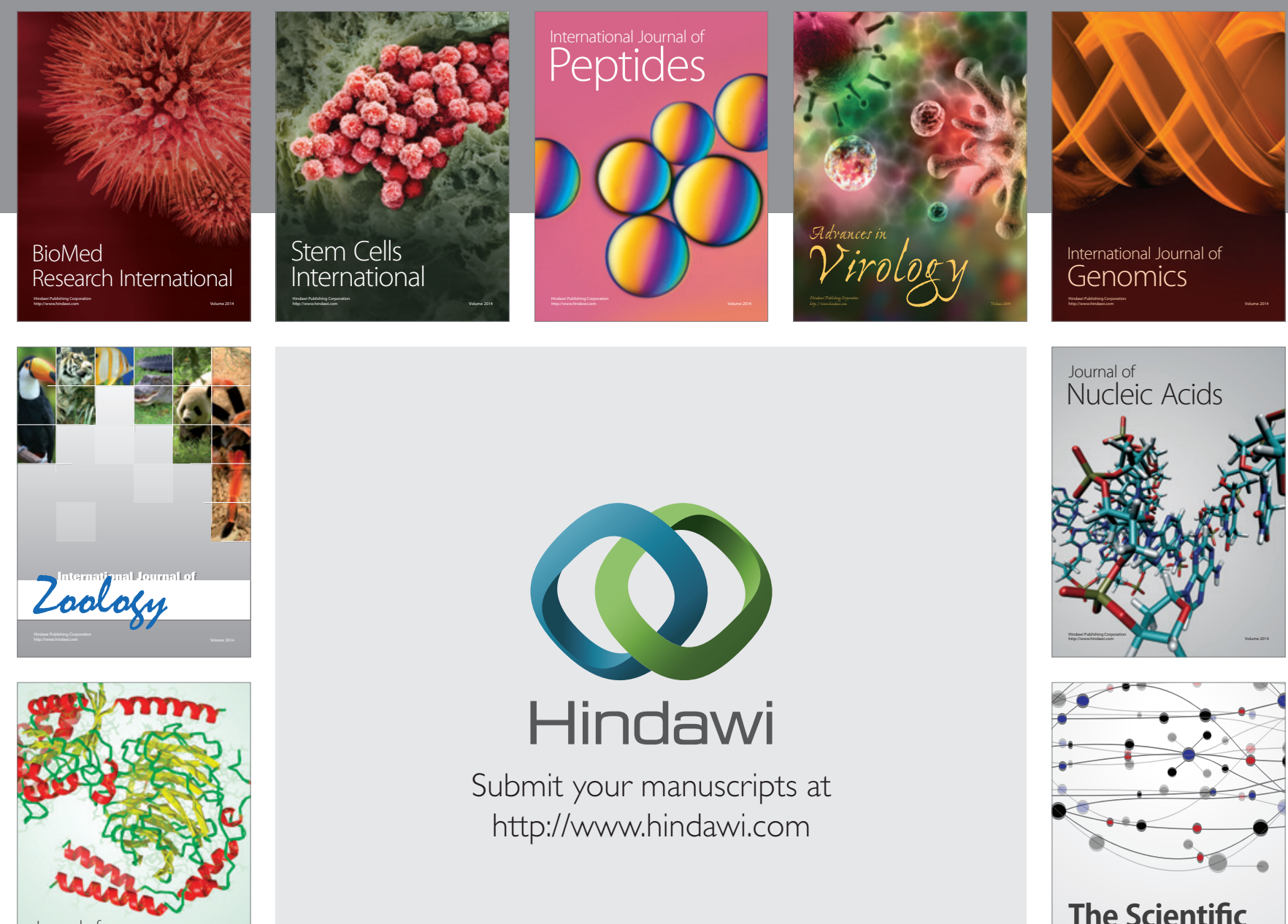

Submit your manuscripts at

http://www.hindawi.com

Journal of
Signal Transduction
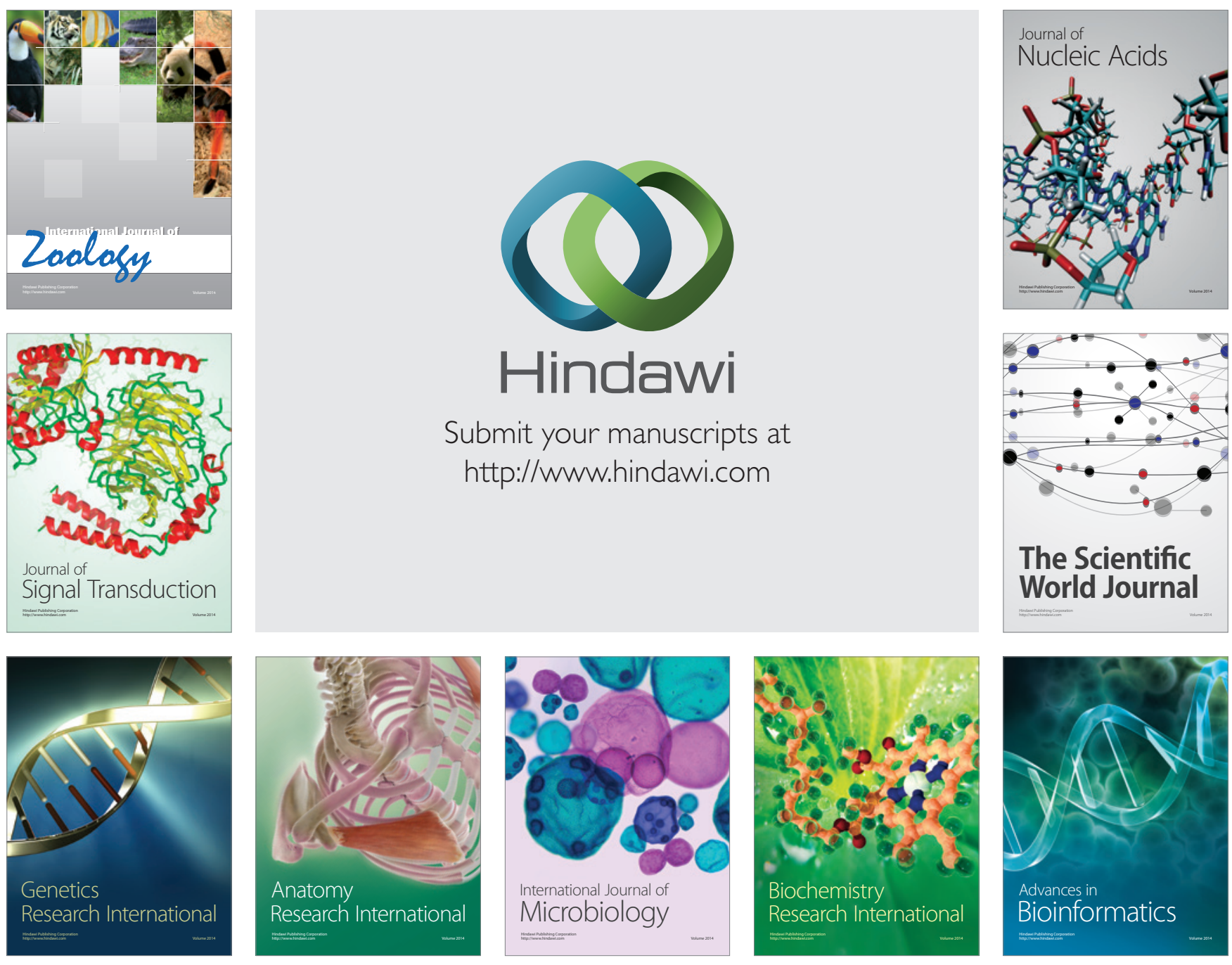

The Scientific World Journal
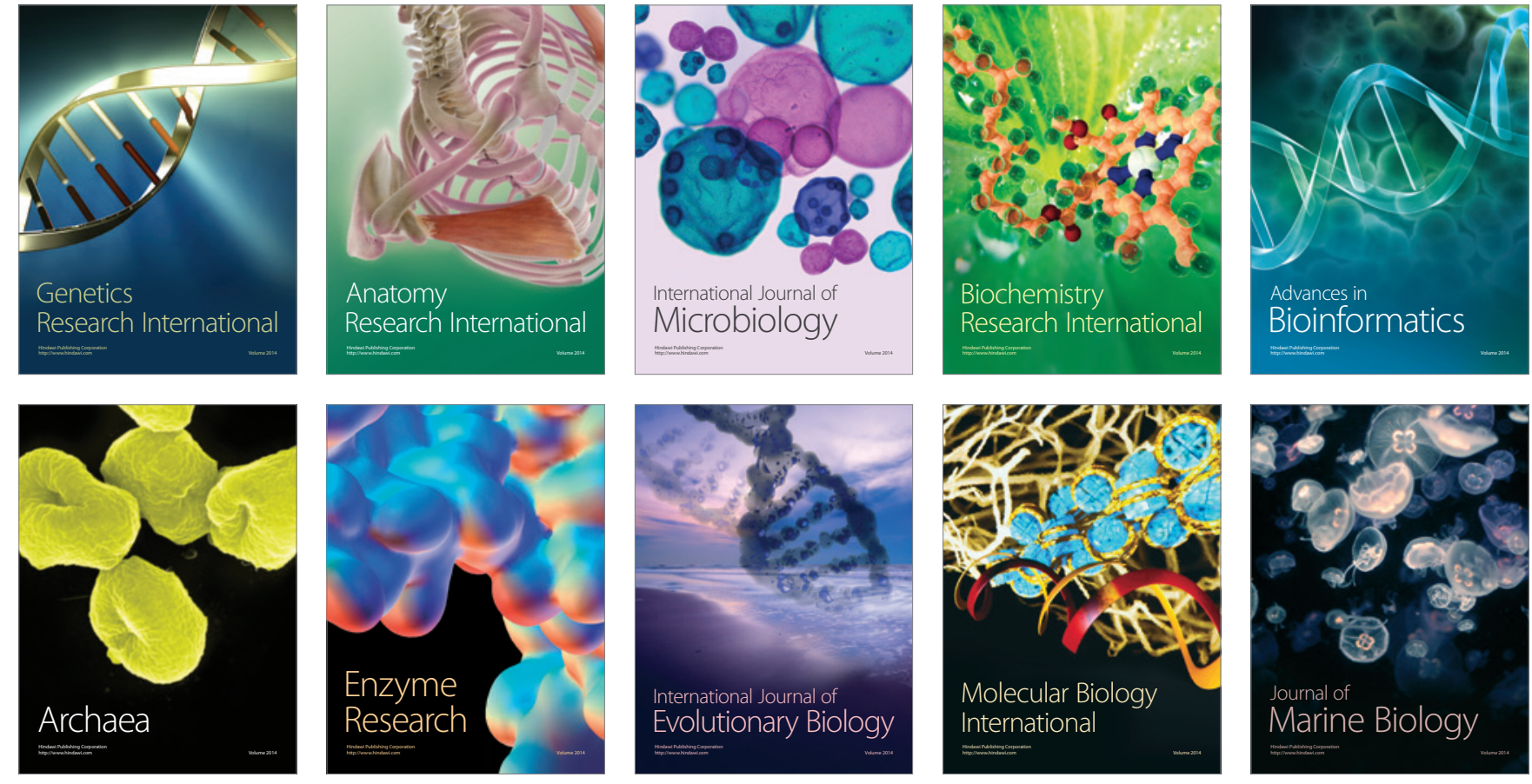